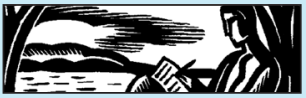

\title{
Real Money, Real Me: Life Told by Third-party Mobile Payment Platforms
}

\author{
Rong Huang
}

Peking University

\section{ABSTRACT IN ENGLISH}

Platforms are constantly shaping online identities. The third-party mobile payment solution is one of the latest technological innovations that have redefined how we lead our lives today. The popularity of third-party mobile payment in China allows platforms greater data power to present users' identities either as individual consumers or as members of a consumption community. This article first introduces the background and data features of third-party mobile payment platforms. It then concentrates on the two dominant platforms, Alipay and WeChat Pay, to demonstrate their different monetary approaches to user identities, characterized respectively by personal finance and by collective belonging. Finally it will discuss in brief further implications, including the possibility of a unified on/offline identity, the identification of an online user, and the issue of privacy protection.

Keywords: Third-party mobile payment, identity, Alipay, WeChat Pay

\section{ABSTRACT IN CHINESE}

网络平台正在不断塑造用户的身份。第三方移动支付是重新定义我们生活方式 的最新科技创新之一。第三方移动支付巨头在中国的普及使其背后的平台拥有 了更强的数据能力来定义用户身份, 可以将用户界定为个体消费者或消费社群 中的一员。本文首先介绍第三方移动支付的背景和数据特点。其次以支付宝和 微信支付两大巨头为例, 说明平台对用户身份定义的两大模式, 即个体勾画模 式和群体认同模式。最后引入对于线上身份的简要讨论, 重点关注网络身份的 唯一性、网络身份认定和网络身份隐私等问题。

关键词：第三方移动支付, 身份, 支付宝, 微信支付 
Identity, as defined by the Oxford English Dictionary (OED), has two subreferences when denoting a special idea of existence:

1. The sameness of a person or thing at all times or in all circumstances; the condition of being a single individual; the fact that a person or thing is itself and not something else; individuality, personality;

2. Who or what a person or thing is; a distinct impression of a single person or thing presented to or perceived by others; a set of characteristics or a description that distinguishes a person or thing from others ("identity, n.").

A comparison of the two reveals key ambiguities concerning identity. The first definition stresses the "oneness" of identity by repeatedly using synonymous words like "sameness," "all," and "single". This corresponds with definitions of identity in other contexts, such as mathematics and science $;^{1}$ it also connects with an individual's desire to form a uniform perception of the self from within, as inherited from the core spirit of humanism, enlightenment, and the modern project of self-seeking. The second definition, however, suggests that a person should be identified from the outside, or from markers that are not innate to the subject under discussion. In this sense, the practical need for social identification outruns the existential inclination of self-assurance. How the self is identified and unified within the very person seems to be less important as how he or she is perceived by others, so that the pursuit of oneness is replaced by the presence of impression, which makes space for flexible and pluralized descriptions of individual identities in constantly changing social contexts.

This pair of OED definitions essentially speaks for the doubleperspective approach that is generally employed by life writers to locate identity: an internal, individualistic perspective and an external, collective perspective. Variations and combinations of the two contribute to the complexity of personal identity. Online platforms are not entirely unlike life writers in their telling of users' identities. In this article, I will show how these two versions of identity are presented by two Chinese thirdparty mobile payment platforms. In the first part I will provide background information about third-party mobile payment services in China, explain the context, and describe the sweep of life data collected by monitoring the flow of money. Part two will examine in detail the two dominant third-party mobile payment platforms Alipay and Tenpay (with a focus on its flagship service WeChat Pay). While both appear to advocate the golden line of "I pay therefore I am," Alipay gears towards the internal approach to users' identity by reinforcing the image of a financially 
capable individual, whereas Tenpay utilizes social media to define users from an external perspective, emphasizing online money as a valued asset for socialization. The last part is a short and tentative discussion about implications. Issues including the possibility of a unified identity, the idea of identification as distinct from identity, and the problem of privacy protection suggest starting points for further discussions.

\section{THE TECHNOLOGY THAT HAS REVOLUTIONISED LIFE}

Third-party mobile payment may refer to any financial transactions, either consumption or investment, realized by a third party who is neither the payer nor the payee, via the use of a mobile device, usually a smartphone or a tablet computer. ${ }^{2}$ It is the latest in a series of technological innovations that have profoundly shaped not only the commercial outlook but also the personal lifestyle of Chinese Internet users. Starting from around 2012 (Dahlberg et al.; Shi and Shen), third-party mobile payment services have swept across the country, transforming all categories of transactions, from online shopping to offline purchasing, into easy scans or swipes of personal smart devices. ${ }^{3}$ This sector's market value has grown exponentially from 0.2 trillion RMB in 2012 to 58.8 trillion RMB in 2016, and in estimation, 307.2 trillion RMB by 2020 (iResearch, "2017 Report"). The instant payment service now available is remarkable in its own way. Apart from easy electronic access to a user's bank account, this kind of payment solution allows users to transfer real money into their mobile payment accounts, which can then facilitate a set of financial options from investment to insurance. For a sweeping metaphor, the current Chinese thirdparty mobile payment service resembles a combination of PayPal's online transferring function, Apple Pay's device-based payment, and banks' access to personal financing, plus thorough updating.

Many factors contribute to the rapid shift from traditional currency payment to cash-free mobile payment. The foundation has been laid by the wide popularity of smart handsets and effortless access to wireless communication, which results in a quicker, more stable mobile web connection (Dahlberg et al). Technological innovations usually turn the world "upside down"; that is, from the people most adaptable to changes, such as the young generation, to those who tend to stay in a more fixed way of life, such as the elder generation. A startling feature of this new technology is its "flattening effect." The convenience of the third-party mobile payment enables it to reach even the farthest corner of technological innovation, and consequently to shape life at the very root. A market grocery vendor who used to rely primarily on a familiar circle 
of customers and therefore was normally the least affected by anything revolutionary, claimed in an interview by Nikkei.com that "if I fail to provide mobile payment access, I will lose customers, as fewer and fewer people are carrying cash with them because mobile payment is just so convenient' ("The Unstoppable Mobile Payment in China”). Her words describe a burgeoning social group whose members are identified by their shared use of third-party mobile payment services. Cash-free has been so widely adopted that a square inch of Quick Response Code and a smart phone are enough to trigger transactions from beans to Benz, from common daily supplies to very expensive luxuries. Significantly, this shift from paying offline to paying online takes only minimal effort and therefore is converting people from all walks of life at an unprecedented speed and scale.

The indisputable two giants in the Chinese market are Alipay and Tenpay, which in combination snatched over $94 \%$ share of this nearly 27.1 trillion RMB market in the second quarter of 2017 (iResearch, "Q2 of 2017 Report"). Alipay started as a payment solution for Taobao, the dominant online shopping site in China; while Tenpay consists of two major mobile payment solutions incorporated respectively as QQ Pay within QQ, the leading online chatting program, and as WeChat Pay within WeChat, which originally was an instant messaging app but has quickly evolved into a leading mobile social networking site. The star service of Alipay is Yuebao, a fund management platform that allows users to make direct cash investment from their account into a money market fund and entitles them to pay any Alipay bill with their account money. Flexibility and high rates of return have made Yuebao the largest market fund in the world, and have helped Alipay to become the largest mobile payment platform in China, with a $55 \%$ share of the entire market (iResearch, "2017 Report"). While personal finance is key to understanding the core practice of Alipay, Tenpay adheres more to the highly successful social media platforms of its parent company Tencent. In the second quarter of 2017, for instance, WeChat's number of monthly active users, a key indicator of an app's influence, reached a record high of 937 million RMB (Statista). WeChat Pay, therefore, is considered an integral part of the virtual society envisioned by Tencent, who wants to build one all-encompassing online ecosystem-an ambition shared by its rival Alibaba, the IT giant behind Alipay. Combing ecology with system to show how online life has become as diverse as real life is not an invention of payment platforms, but the idea of an ecosystem based on online transactions advances digital life to a more acutely felt stage.

The prevalence of third-party mobile payment provides platforms with new channels for collecting huge flows of data. The wide acceptance 
of Tenpay and Alipay means that the IT companies behind them are able to analyse users' behaviours with unprecedented range and accuracy. Apart from common denominators like location, movements, spending, social circle, and activities during a user's active time, platforms are now confident enough to discuss behavioural patterns when a user is not using the app. Notably on World Sleep Day (March 21st) of 2016, WeChat published a sleep report, suggesting that people born after the year 2000 enjoyed the longest sleep hours. ${ }^{4}$ Certainly, this statistical outcome is not beyond suspicion, but WeChat clearly feels sufficiently comfortable to make deductions about users' behaviors even when they are not directly logged in. WeChat's confidence derives from users' reliance on the platform. The difference between online and offline can no longer be easily distinguished by a user's deliberate choice to stay "logged out." This case speaks eloquently to both a user's reliance on powerful platforms and the never-ceasing nature of data collection online in determining identity.

\section{MONEY IN PLAY}

The scale and scope of data collection is directly linked to the potential of platforms for the interpretation and exploitation of information. The Economist compared this age of data-mining to the mining of coal in the $19^{\text {th }}$ century, and predicted enormous profits to come ("The World's most Valuable Resource"). Indeed, data is generating considerable profits for IT conglomerates like Tencent and Alibaba. With the spread of third-party mobile payment services, platforms utilize money as a key component when interpreting user identity. Alipay and Tenpay are now capable of presenting a version of who a user is based precisely on how they use their money. Initially a payment solution for individual users, Alipay conducts identity interpretation tailored for each user by focusing on personal financial choices. In contrast, because Tencent established an online ecosystem through its dominant social media services, such as WeChat, WeChat Pay encourages users to circulate money within their online social circles, and sketches identity on a collective basis. Personal or collective, both platforms follow the logic of "I pay therefore I am," applying a seemingly solid foundation of purchase history to the representation of identity in a virtual world.

Undoubtedly Alipay is the pioneer of third-party mobile payment service providers in China. A Chinese consultancy, iResearch, describes Alipay's ecosystem as 'based on the essence of finance,' for it grasps with precision the very basic need of individual users to manage their 
money at will ("2017 Report"). Alipay succeeds because it breaks down a variety of payment barriers. First, it has created a platform where a user can access money from bank accounts, pay bills, and optimize investment, all with their fingers. Second, Alipay is constantly offering convenient payment methods, from easily accessible QR codes to technologically-embedded payment choices like sound wave, fingerprint, and facial recognition. Third, payment scenarios have been expanded and unified. Step-free entrance is provided for small business owners to join Alipay's ecosystem. Moreover, Alipay is actively establishing partnerships with large entities in key areas of the public sector. According to the platform,

... by the end of 2016, there are 357 cities (including county-level cities and municipalities) on the Alipay city service platform throughout the whole country. There are nine categories of services, covering 380 specific items. The services include car owner services, government services, medical services, transportation and livelihood payments (Ant Financial).

With an ever-growing market and an increasingly user-friendly mobile payment society, Alipay gathers gigantic amounts of data, which is stored, analysed, processed and presented back to users to tell them who they are.

The annual spending bill provided by Alipay at the end of every year opens an interesting window on how the platform considers its users. The bill may look like a personal financial report, but on closer inspection it turns out to be something rather different, and altogether more ambitious in scope. A financial report from a bank usually contains hard facts including figures, places, time, parties involved in the transaction, elements that require no further interpretation. Alipay is definitely not the first IT company that attempts to engage users by offering them scraps of themselves, but it is the one that foregrounds narrative in its representation. ${ }^{5}$ For example, the following words appeared on the cover of its 2016 bills:
Record · Reward
In the year of 2016
Millions of things happened
That might have gone unremembered.
It's alright
Because bills remember them all. ${ }^{6}$

This almost poetic wordplay dissects the notion of remembering into the action of recording, and offers a reward for remembrance, portraying 
money not simply as an approximation of memory but also a far more reliable source than personal recollections. As memory defines a person, it also distorts, conceals, and fakes, which Alipay takes as the breaking point to represent a solid identity. Combined, the two title words "jiyi" ("Record - Reward") literally mean "remember" in Chinese. If memory makes us human, what Alipay ventures to substitute is the very essence of human existence by such deliberate designs, so that identity is ultimately defined and determined as contained within the platform instead of in the user. Unlike human memory, the purchase data used by Alipay to define identity is hard to dispute, leaving little space for identity shifts.

A similar preference for narrative extends to Alipay's portrait of the individual consumer. As early as 2012, Alipay told me that I was a "Beauty Fighter." The accompanying tags explained that "beauty" was a pun that referred both to a consumer of beauty products, and to someone who is good at getting beautiful goods at a reasonable price, because in Chinese the adjective "mei" ("beautiful") can refer to things that are both satisfactory and inexpensive. Alipay took a step further and composed another poetic narrative for me:

Don't have a red eye for the rich;

Don't care how others judge;

Don't go crazy after big brands.

Buy only what I like.

My shopping, my call! ${ }^{7}$

This was striking not only because of its amateurish mimicry of verse composition. One remarkable tendency is the platform's apparent need to apply narrative skills to turning someone with limited money to spend into someone who was determined, assertive, and independent. The three "don'ts" at the beginning of the first three lines actually suggest a positive attitude from negative expressions. The delimiting attributive "only" in the fourth line further paints a sense of assertiveness. The last line resembles a propaganda catchphrase that has the effect of saying something other than the truth. Although I knew this message was generated because my buying power was below average, I did share it among my friends, with an online feedback stamp thoughtfully provided by Alipay. Some of those stamps were self-mocking ones like "hard to see", "blind my eye", "I'm wrong" or even "c'est la vie". Alipay thus created an enclosed online language system in which the production and deconstruction of meaning went hand in hand. Users are guaranteed a certain degree of freedom in defining identity, but only within the framework prescribed by the digital platform. 
A friend of mine, who kindly shared her spending bill with me, offered a different version. As a more generous consumer, her portrait read:
The Goddess in Prada
Fashion is my true colour.
Quality is my incessant pursuit.
I care not for price when I shop;
For the real value is what I say!

Obviously this description was generated for someone who exhibited above-average consumption power. Differences in the narrative include positive declarative sentences and the affirmation of a conqueror of fashion shopping, going so far in the last sentence as to endow her with the authority to determine value. My friend and I represent two groups of the population stratified by Alipay according to their willingness and power to pay online. Absurdity aside, the intention speaks louder than the actual practice. Alipay is designed to be personal and intimate. Though the portraits of my friend and me are distinct in almost every way, both repeatedly mention the same pronoun "I" and its possessive form "my." Through this exclusive use of the first-person pronoun, Alipay speaks for the user when answering the underlying question of "who I am." Instead of suggesting a kind of otherness by using second- or third-person pronouns, Alipay renders itself invisible, leaving only one version of self for users to compare, identify, and acknowledge.

Predictably, the question of "Is this really me?" became confusing after these bills were available to users, since they usually represented a much greater spender than most customers might have imagined themselves to be. In fact, figures were widely miscalculated, and non-consumption transactions were included to create a highly exaggerated number. For instance, I once deposited 5,000 RMB to purchase a short-term bond issued on Alipay. This transaction was later listed as "online shopping" because there was no subcategory for investment. After the bond expired, the money would be returned to my Alipay account for further use. In theory, then, this money could be listed as being spent again and again, furnishing me with a bill resembling that of a millionaire. Other people also had similar experiences; many discovered that what they "spent" far exceeded what they earned. One bitter netizen remarked that the bill was 'merely drafted by a bureau of statistics controlled by laymen who provide nothing but figurative illusion' (QLab42). Inaccurate figures eventually produce an alienated self-perception as a money spender, saver, and manager. The presence of real money on social media therefore widens the gap between the online self that is understood by individual users as an extension of their daily self-awareness and the algorithmic 
self that is analysed for behavioural patterns leading towards profit by IT companies.

Yet Alipay defends its outlook. Xue Bai, a researcher from Ant Financial Business School, another branch of Alibaba, responded to complaints about the many flaws in those bills by explaining that 'spending in Alipay is not exactly spending in the traditional sense' (Tang). According to her, spending should not be restricted to payments that actually decrease monetary value. Loans on credit or from banks, insurance, and personal finance are important aspects of spending that tell a fuller story of a person as a consumer. Bai admitted the possibility of repeated calculations, but placed greater emphasis on what could be learned from the flow of money than from any single payment which could only be accounted for as a one-off transaction. In contrast to a bank statement, which faithfully presents the actual value of money-in and money-out, helping customers lead a life well balanced between spending and depositing, Alipay bills focus instead on the mobility of money and frequency of transactions. In my case, the platform might conclude that because I could carry out a $5000 \mathrm{RMB}$ transaction, it was probable that more similar transactions would follow, therefore adding to the total value they estimate from me. The key to such a version of the self as a money spender rests not on an actual balance, but on a user's potential, power, and willingness to spend money in all sectors, whether investment or consumption.

Accurate or not, these bills have been hugely successful among the public and the media. People share their bills on personal social media, often with self-mocking comments or self-assuring words. Whether the bill reflects actual spending is less important than the sharing, which creates another online scenario, as users offer one more layer of their identity through the interaction with the one Alipay provides. In this case the quality of the bill becomes irrelevant; its simple presence is enough to encourage identification. Media reportage grasped this very spirit through one repeated headline: 'Alipay's Annual Spending Bill Going Viral Online. ${ }^{8}$ Once more Alipay breaks a barrier, as individual users, traditional media, and online platforms come together to talk about money.

Alipay's strength lies in the data analysis of individual financial flows. Tenpay, however, represents its users from a social perspective, and especially through its flagship service WeChat Pay. Bringing money back into social exchanges is its most prominent feature. People are valued not by how much they earn, but by how much they are prepared to invest in social media. Take for example the number and value of red envelopes. In Chinese tradition, people put money in red envelopes and give the envelopes to those going through life's major and often costly events-weddings, funerals and births, for instance. Children also 
receive red envelopes during the Spring Festival, the traditional Chinese New Year, as their pocket money for the coming year and as a symbol of good wishes. Red envelopes might be the only custom other than formal transactions where money can be publically circulated as a gesture of a strong relationship without the danger of causing any embarrassment. In 2014 WeChat Pay made this practice electronic by allowing people to send money in virtual red envelopes to their WeChat friends. It then promoted this function by launching a lucky draw competition, in which a red envelope is sent to a WeChat group, with a certain number of members receiving different amounts of money from the total on the principle of "first come, first serve." Afterwards, group members may access the record of how much money was posted and how much each person was assigned. Partly because of such elements of play and competition, the online red envelope has gained enormous popularity. On 20 May 2017, when the three numbers of the date 520 (May is called the "fifth month" in Chinese) corresponded with the Chinese pronunciation of "I love you," WeChat users sent each other over 1.38 million red envelopes as an expression of love in the first minute of that day. ${ }^{9}$ The message imparted by the platform as it adjusts the normal bar of $200 \mathrm{RMB}$ for each red envelope to $520 \mathrm{RMB}$ on this special day is that being a lover means to be willing to send out money. Love is monetized; digital money becomes a playful and highly favoured currency for sustaining even the most intimate relationships.

The need for socialization became WeChat Pay's invisible but invaluable guide when constructing its own financial system within its already formidable online community. Today transactions play a central role in the general design of WeChat. On 15 June 2016 WeChat posted a short animated film entitled "One Day with WeChat," another creative advertisement distributing its latest propaganda. Among the nine scenarios represented (morning reading, breakfast, commuting, working, shopping, group lunch, team bonding, games, and bedtime greeting), four scenarios (breakfast, shopping, group lunch, and team bonding) involve WeChat Pay, and at least two more scenarios can incorporate this service (for example, to pay for the commute, and to buy virtual items for an avatar in an online game). The frequent appearance of money in the video proves that money-related activities have become crucial factors for connecting online and offline life, requiring users to stay perpetually logged in. Relationships again appear to be more and more monetized. Money is circulated among business partners, friends, close relations and intimates. Sending money directly to each other is not considered unbecoming or offensive, but justified as an expression and confirmation of the relationship bond. 
Socialization can be double-edged. According to Penguin Intelligence, a research institute of Tencent, in 2016 over $90 \%$ of WeChat users stayed with the app for more than an hour on a daily basis, but even such a shocking figure has not been fully transformed into WeChat Pay's influence. The same report also reveals that while $84.7 \%$ of WeChat users sent out red envelopes, only half accessed other payment functions of WeChat Pay, such as insurance and investment. The red envelope attracts a huge flood of users, but the amount of money each red envelope contains is often more symbolic than significant macro-economically. Half of WeChat Pay users spend less than 300 RMB (approximately 45 US dollars) monthly, as stated by Chatterbox, the Official WeChat Blog. In contrast, people born after the $1980 \mathrm{~s}$, the generation considered to be the major force online, spent over 10,000 RMB with Alipay in 2016, or more than $800 \mathrm{RMB}$ a month (Ant Financial). Insufficient capital flows therefore leave WeChat Pay with insufficient data to construct as thorough a portrait of a personal user as Alipay does.

In its promotional efforts, WeChat Pay chooses an impersonal style of portrayal, appealing to the image of a young and innovative community bonded by their loyalty to the app. In the advertisement video "One Day with WeChat," the protagonist is depicted as someone cut from a blank paper. Judging by the hair style, the short shirt, and the body build, the figure is probably male. But other than gender, no other labels can be attached. The signature green colour of WeChat is the only colour beyond the paper white of the protagonist and the natural wooden feature of the background. Choosing green as the colour of WeChat suggests an ambition to ally the app with other major communication apps around the world; for instance, LINE, WhatsApp, and FaceTime are all in green. And WeChat Pay may add another implication for the colour. In this minimalist video, trees are the only green presence besides WeChat-related components. Green in particular marks everyone involved in a WeChat Pay scenario. The arrangement of the same colour between trees and WeChat Pay could suggest that this third-party mobile payment function is environmentally friendly as it uses no paper, thus calling for more people to join the community to share a just cause. Scenes in which others are seen in the same green colour integrate WeChat Pay into a sense of social belonging, with the protagonist as a representative welcoming all to join in the online community connected by WeChat Pay.

This video is not the first time that WeChat tried to define its community through the representation of an anonymous, non-specific figure. In 2015, less than a year before "One Day with WeChat," WeChat published "Life with WeChat, a White Paper." In this new promotion, WeChat places 
Moments, the functioning model on WeChat where one can share life bits with friends at the centre of online social life as revealed in this timeline entitled "A Typical Day of a WeChat User:"

$\begin{array}{ll}\text { 07:00 } & \text { Getting up } \\ 07: 45 & \text { Commuting } \\ 08: 30 & \text { Near the workplace } \\ 09: 00 & \text { Start working } \\ & \\ \text { 10:00 } & \text { Morning break } \\ \text { 12:00 } & \text { Ordering Lunch } \\ \text { 12:45 } & \text { Lunch break } \\ \text { 17:00 } & \text { Ready to be off } \\ \text { 18:00 } & \text { On the way home } \\ & \\ \text { 20:00 } & \text { Watching TV }\end{array}$

Flipping through Moments Reading online articles \& gaming Buying breakfast with WeChat Pay Dealing with work-related group messages Moments \& Personal Messages Paying with money in red envelopes Online shopping \& group chatting Flipping through Moments Paying for dinner grocery with WeChat Pay

Reading, Moments, send out Likes, online chatting, gaming \& shopping

The highly compartmentalized allocation of each time period is possible only because WeChat offers a full range of functions both for work and off-work life. Such a rigid timetable can hardly suit everyone, but the general breakdown of the waking time and the range of common activities will strike a chord. Absolute anonymity guarantees free access for all to enter. The many things listed on the right column foster an impression that the platform is all that is needed to live a unique and interesting life. As the chief social space of WeChat, Moments is mentioned four times, where WeChat Pay and red envelopes are mentioned three times. This frequency indicates the important role played by mobile payment in the creation of social recognition. The timetable is therefore less a description of someone's life than the community guideline envisioned by the platform for its potential users. WeChat's approach is not to generate individual identity, but to propel the process of community identification through online interaction marked by money.

\section{TOWARDS A UNIFORTM ONLINE IDENTITY?}

Though in the new form characterized by online money, in a sense, Alipay and WeChat Pay are telling the old story of identity being determined by life as a unique individual or as a member of a community. Defining 
identity is notoriously complicated, but IT companies, who have proved very efficient in making things handy, aim to simplify this business of identification to its basics. Marc Zuckerberg, CEO of Facebook, clearly and loudly spoke out his belief.

\footnotetext{
'You have one identity,' he says emphatically three times in a single minute during a 2009 interview.

'The days of you having a different image for your work friends or co-workers and for the other people you know are probably coming to an end pretty quickly.'

'Having two identities for yourself is an example of a lack of integrity... [T] he level of transparency the world has now won't support having two identities for a person.' (Kirkpatrick 199)
}

These words proved prophetic. And yet, while being in theory a harbour for infinite self-remodelling, platforms like Facebook are exploring the other end, one that is far from barrier-free. Though to this day Zuckerberg criticizes double identities from a moral high ground, Facebook must continually recognize itself as a swamp of identity frauds, coaxes, and thefts. In most cases, Facebook identities are only understandable as a plurality.

A unified online user identity is crucial as van Dijck sharply remarks that platforms 'have a vested interest in pushing the need for a uniform online identity to attain maximum transparency, not only because they want to know who their users are, but also because advertisers want users' "truthful" data' (200). Users' identities are considered engines for future profits, which drives companies like Facebook to find a solution to identity unification. Finding the keys to turning malleable identities into the online language necessary for coding and programing remains a major challenge. Speaking from a technical point-of-view, Todd Schraml, while admitting the difficulty of automating "the customer identification process,' foresees that a '(far too rare) option ... is to embed your organization's customer identification process within the operational systems initiating the customer transactions' (48). Third-party mobile payment platforms have already carried out Schraml's prediction by sewing together the many aspects of life with the thread of money, thus offering a solution for the uniqueness of identity. Affordability, or the ability to pay, rewards the payer with a powerful sense of control and fulfilment, shaping their identity: "I buy therefore I am." This consumerist cogito ergo sum has already been implanted by platforms like Alipay and WeChat Pay to record, trace, and analyse users' identities.

Another consideration Zuckerberg fails to take into account when attempting to impose the singularity of identity on users is the difference 
between identity and identification, which ultimately leads to many identity confusions on Facebook. To be precise, there will always be confusions when talking about identity, because 'disobedient subjects,' to borrow Gillian Whitlock's term (ix), are perpetually curious about or seeking unconventional possibilities of life. For online platforms, however, the need for solid identification is strong, because for consumerist purposes they want to establish a clear correspondence between the identified and the identifier. Zuckerberg's vision represents a common wish of online platforms to integrate the two worlds of online and offline. In other words, identifying the entity who accesses their service with the physical, flesh-and-blood, real-life money earner is the key to their success. Nevertheless this does not mean that represented identity must be singular. In fact, both Alipay and WeChat Pay allow users to post fake names, inauthentic photos, and other unrealistic information to their account avatar. But before that, individual users have to complete a real-name registration process so that platforms can always match the online avatar with the actual payer. ${ }^{10}$ This information is however kept confidential, unless the user prefers otherwise. Thus the real identity of a user is kept private to other users while the platform knows who is paying.

Yet why would someone insist on having this information revealed? While the real-name registration process is crucial for platforms to identify their users, it can also serve as a safety assurance among users in the same online community. But identity information online has posed dire challenges to privacy protection, even on powerful platforms like Alipay. Users may suddenly find that it is almost precarious to maintain their real-life identity online. On 1 January 2018, Alipay launched the annual spending bill of 2017. The cover words now appear in three more neutral but still warm lines: 'Time always flies without being noticed/Open the bill/And see if it was a year you didn't quite expect.'11 The abandonment of the traditional 'knowing them all' cover might derive from the increasing pressure of privacy concerns. Alipay never had the opportunity to fully explain the change, because the whole nation was furious after one lawyer complained on Weibo, China's counterpart of Twitter, that Alipay's bill was now set up to share users' data with its commercial partners without sufficient notification to individual users (@Yueshenshan). It turned out that a very small section on the 2017 cover contained an agreement that would allow Alipay to do so. What enraged the nation was that because the box was automatically checked, many people never knew that they had given permission until the lawyer's complaint hit national breaking news. Alipay reacted swiftly, admitting that this default permission was 'extremely foolish and stupid' on its official Weibo account (@ZhimaCredit) and cancelling the agreement the very next day. But this incident 
hit a public nerve. On 6 January 2018, the Cyberspace Administration of China, the country's regulator of information technology, issued summons to three IT giants, including Alipay, over their failure to protect customer data ("Heads Summoned"). This incident reveals the imbalance of data power. A user may forget the details of an authorization, but online footprints keep everything in check. While companies use data to make money, the users who provide the data in the first place still remain largely unaware of what has been collected and how their data is utilized. To stay real online could mean that the user becomes easy prey for profitdriven companies looking to launch customer-specific market plans.

Behind the convenience and the controversies, the exact extent to which third-party mobile payment has revolutionized everyday life remains unclear, in part because the service keeps evolving at a speed rarely witnessed in history. To be sure, the connection between online and offline has become almost seamless. For people who rely on the thirdparty mobile payment services to pay for almost everything in daily life, every penny used in the physical world leaves an online imprint. The accumulation of such data results in a representation of a person both as an individual consumer and as a member of a social circle distinguished by shared consuming habits. In this sense, offline and online together recreate identity. A platform knows its users primarily by what they have done in real life, particularity what they have purchased, and not by what they claim to be with an online avatar. But the massive amounts of data being drawn from the world we inhabit is increasingly enhancing platforms' power to create detailed, and highly monetized portraits. New forms of representation will present new challenges, and privacy is increasingly at risk. Thus the old, ambiguous, and troubled issue of identity is breeding new forms and problems in this information age.

\section{ACKNOWLEDGEMENTS}

I started this article during my visit at King's College London for the 2016-2017 academic year. Many people must be acknowledged for making it possible. A preliminary version was presented at the IABA-Europe conference in June 2017. I must thank members from my panel for their constructive comments. Also I am particularly grateful to Clare Brant and Robert Gallagher, for their enlightening editorial input. Last but not least, I am much indebted to Craig Howes, whose generous support and meticulous suggestions have accompanied this article from its infancy. Quite a number of materials that I use in this article are in Chinese, though some of them appear bilingually. I did all the translations unless otherwise indicated. 


\section{WORKS CITED}

@Yueshenshan. "Please read the Following before you Open Your Alipay Annual Spending Bill." Weibo 2018. 13:12 p.m., weibo.com/yueshenshan?nick=\%E5\% B2\%B3\% E5\%B1\% B $\mathrm{E} \% \mathrm{E} 5 \% \mathrm{~B} 1 \% \mathrm{~B} 1 \&$ noscript $=1$.

@ZhimaCredit. "About the Default in Alipay's Annual Spending Bill.” Weibo 3 Jan. 2018. 23:24 p.m., weibo.com/zhimateam?is_hot=1\#_rnd1516005835157.

Ant Financial. "Moving Towards a Better Society for the Future: Ant Financial 2016 Sustainability Report." 20 May 2017. os.alipayobjects.com/rmsportal/omkAQCxPyHDDqtqBDnlh.pdf.

Dahlberg, T., J. Guo and J. Ondrus. "A Critical Review of Mobile Payment Research." Electronic Commerce Research and Applications 14.5 (2015): 265-284.

"Heads of Alipay and other Two IT Companies Summoned after the Annual Spending Bill Crisis." The Office of the Central Leading Group for Cyberspace Affairs, 10 Jan. 2018. www.cac.gov.cn/2018-01/10/c_1122234687.htm.

“identity, n.” OED Online, Oxford University Press, Jun. 2017. www.oed.com/view/Entry/91004. Accessed 18 Oct. 2017.

iResearch Inc. "2017 China's Third-Party Mobile Payment Report.” Jun. 2017. www.iresearchchina.com/Upload/201707/20170714103414_2982.pdf.

iResearch Inc. "China's Third-Party Online Payment Market in the Q2 of 2017." 13 Oct. 2017. wreport.iresearch.cn/uploadfiles/reports/636435069492442217.pdf.

Kirkpatrick, David. The Facebook Effect: The Inside Story of the Company that Is Connecting the World. London: Simon \& Schuster, 2010.

"Life with WeChat, a White Paper." Tencent Technology 23 Oct. 2015. tech. qq.com/a/20151023/057238.htm\#p=6.

"One Day with WeChat." QQ.com, uploaded by the WeChat Team, 15 Jun. 2016. v.qq.com/x/ cover/cafr5o86dlenelb/u00206jejjt.html.

Penguin Intelligence. "The Influence Report of WeChat." 21 Mar. 2016. tech. qq.com/a/20160321/007049.htm\#p=1.

QLab42. Comments on "How to Evaluate Alipay's 2016 Annual Spending Bill?” Zhihu.com 6 Feb. 2017. www.zhihu.com/question/54419487/answer/139252846.

Schraml, Todd. "I Buy, Therefore I Am." Intelligent Enterprise 3.7 (2000): 46-52.

Shi, Yulu and Yue Shen. "Development of Mobile Payment in China: A Short Review." Technology and Market 16.7 (2009): 19.

Statista Inc. "Number of Monthly Active WeChat Users from 2nd quarter 2010 to 2nd quarter 2017 (in millions)." Jul. 2017. www.statista.com/statistics/255778/number-of-activewechat-messenger-accounts/.

Tang, Zizi. "Freaked out by Your Alipay Bill? It Truly Served You Right..." Southern Weekly Paper oeeee.com, 6 Jan. 2017. www.oeeee.com/mp/a/BAAFRD00002017010624088. html.

"The 2016 WeChat Data Report." Chatterbox 29 Dec. 2016. blog.wechat.com/2016/12/29/ the-2016-wechat-data-report/\#more-4961.

"The Unstoppable Mobile Payment in China, Where WeChat Leads." Nikkei.com 27 Mar. 2017. cn.nikkei.com/china/ccompany/24357-2017-03-27-04-54-00.html.

"The World's Most Valuable Resource." The Economist 6 May 2017, p. 7.

van Dijck, José. "You Have One Identity": Performing the Self on Facebook and LinkedIn." Media, Culture Eै Society 35.2 (2013): 199-215.

Whitlock, Gillian. Autographs: Contemporary Australian Autobiography. St. Lucia, Qld: University of Queensland Press, 1996. 


\section{ABOUT THE AUTHOR}

Rong Huang is currently a postdoctoral fellow at The School of Health Humanities, Peking University, where she works on the intertwining between life writing and medical humanities. She holds an MA in English Language and Literature and a Ph.D. in Comparative and World Literature. Her research interests include autobiographical narratives, contemporary world literature in English, theories of the body, and media studies. She has published articles about life writing, world literature and new media. Email: huangrong@pku.edu.cn.

\section{NOTES}

1 As, for instance, in the philosophical idea of 'absolute identity,' the logical law of identity, the mathematical reference of identity, or the administrative usages of identity cards and identity certificates, the word implies a certain expectation of sameness. See the OED entry for "identity, n."

2 Definitions of the third-party mobile payment vary, as the technology evolves and also as contexts differ. Here I define the term by foregrounding the two keywords of "third-party" and "mobile." For other definitions, see Dahlberg et al.

3 Third-party mobile payment solutions appeared much earlier both in the world and in China, almost right after the emergence of smart phones. In this article I highlight 2012 as the beginning of real changes, for it was in this year that Alipay launched Yuebao, its core service that has come to redefine the whole industry.

4 The original report is no longer available, but screenshots containing statistics and analyses have been uploaded and circulated online. See a summary by TechWeb on 22 Mar. 2016. Retrieved from mp.weixin.qq.com/s? src $=3 \&$ timestamp $=1508912739 \& v e r=1 \&$ sig nature $=$ tz8dO6Vv5d*FT2s1Wc9iohdDJvaejOzzOVcxiNWOLhj5hFERgZcJDx0VmcmH DIN6AIZb*tnwgVYvgQg4zrz6ZoYrq1LOI3kfvDMvH*BxImRchEQYe3bKD63oseXzLVa RFEXjeifnrlkxhobDC1D7Sg.

5 Famously, in 2011 Facebook launched Timeline to present a visually inclusive profile of a user.

6 Each year the bill can only be accessed by individual users for a certain amount of time. Now the original contents are no longer available, but many people saved theirs and posted their bills online.

7 Alipay tried to describe its user for the first time in 2012. This is the only annual bill page that remains in the public domain and can be accessed with Alipay's account and password. Descriptions of myself and my friend are all retrieved this way from zd.alipay.com/ ebill/annual2012.htm. Accessed 20 Oct. 2017.

8 Alipay's 2016 spending bill was reported by all major Chinese news agencies. Among others, there were the state news agency, Xinhua News (news.xinhuanet.com/video/ sjxw/2017-01/07/c_1120264457.htm); a major portal web, Sina.com (tech.sina.com.cn/ i/2017-01-04/doc-ifxzczfc6910056.shtml); and even the platform held by Alibaba's archrival Tencent, QQ.com (finance.qq.com/a/20170105/021960.htm).

9 The original report published by Tenpay is no longer available, but it has been widely quoted in news reportage; for instance, by the major portal website Sohu.com on 22 May 2017. See www.sohu.com/a/142461326_492251. 
10 The real name registration system requires users to provide valid ID information when accessing the Internet or certain online services. The discussion of real name registration in China can be traced back at the turn of this century. Since then the registration process has gradually been implemented by blogging sites, online storage sites, telecommunication service providers, and third-party mobile payment platforms. It remains an ongoing process today and debates about the cons and pros can be heard from the public, academia, and the administration.

11 The 2017 spending bill can only be accessed via the Alipay app. There are no website links to this year's spending bill. 